\title{
Droplet Combustion Experiments Aboard the International Space Station
}

\author{
Daniel L. Dietrich • Vedha Nayagam • Michael C. Hicks • Paul V. Ferkul • \\ Frederick L. Dryer • Tanvir Farouk • Benjamin D. Shaw • Hyun Kyu Suh • \\ Mun Y. Choi · Yu Cheng Liu • C. Thomas Avedisian • Forman A. Williams
}

Received: 20 December 2013 / Accepted: 19 May 2014 / Published online: 4 June 2014

(C) Springer Science+Business Media Dordrecht 2014

\begin{abstract}
This paper summarizes the first results from isolated droplet combustion experiments performed on the International Space Station (ISS). The long durations of microgravity provided in the ISS enable the measurement of droplet and flame histories over an unprecedented range of conditions. The first experiments were with heptane and methanol as fuels, initial droplet droplet diameters between 1.5 and $5.0 \mathrm{~mm}$, ambient oxygen mole fractions between
\end{abstract}

D. L. Dietrich $(\square) \cdot$ M. C. Hicks

NASA John H. Glenn Research Center, 21000 Brookpark Road, Cleveland, OH 44135, USA

e-mail: Daniel.L.Dietrich@nasa.gov

V. Nayagam

Case Western Reserve University, Cleveland, OH, USA

P. V. Ferkul

Universities Space Research Association, Cleveland, OH, USA

F. L. Dryer

Princeton University, Princeton, NJ, USA

T. Farouk

University of South Carolina, Columbia, SC, USA

B. D. Shaw

University of California, Davis, CA, USA

H. K. Suh · M. Y. Choi

Kongju National University, Chunan, South Korea

H. K. Suh

e-mail: hksuh@kongju.ac.kr

Y. C. Liu · C. T. Avedisian

Cornell University, Ithaca, NY, USA

F. A. Williams

University of California, San Diego, CA, USA
0.1 and 0.4 , ambient pressures between 0.7 and $3.0 \mathrm{~atm}$ and ambient environments containing oxygen and nitrogen diluted with both carbon dioxide and helium. The experiments show both radiative and diffusive extinction. For both fuels, the flames exhibited pre-extinction flame oscillations during radiative extinction with a frequency of approximately $1 \mathrm{~Hz}$. The results revealed that as the ambient oxygen mole fraction was reduced, the diffusiveextinction droplet diameter increased and the radiativeextinction droplet diameter decreased. In between these two limiting extinction conditions, quasi-steady combustion was observed. Another important measurement that is related to spacecraft fire safety is the limiting oxygen index (LOI), the oxygen concentration below which quasi-steady combustion cannot be supported. This is also the ambient oxygen mole fraction for which the radiative and diffusive extinction diameters become equal. For oxygen/nitrogen mixtures, the LOI is 0.12 and 0.15 for methanol and heptane, respectively. The LOI increases to approximately $0.14\left(0.14 \mathrm{O}_{2} / 0.56 \mathrm{~N}_{2} / 0.30 \mathrm{CO}_{2}\right)$ and $0.17\left(0.17 \mathrm{O}_{2} / 0.63\right.$ $\mathrm{N}_{2} / 0.20 \mathrm{CO}_{2}$ ) for methanol and heptane, respectively, for ambient environments that simulated dispersing an inertgas suppressant (carbon dioxide) into a nominally air (1.0 atm) ambient environment. The LOI is approximately 0.14 and 0.15 for methanol and heptane, respectively, when helium is dispersed into air at $1 \mathrm{~atm}$. The experiments also showed unique burning behavior for large heptane droplets. After the visible hot flame radiatively extinguished around a large heptane droplet, the droplet continued to burn with a cool flame. This phenomena was observed repeatably over a wide range of ambient conditions. These cool flames were invisible to the experiment imaging system but their behavior was inferred by the sustained quasisteady burning after visible flame extinction. Verification 
of this new burning regime was established by both theoretical and numerical analysis of the experimental results. These innovative experiments have provided a wealth of new data for improving the understanding of droplet combustion and related aspects of fire safety, as well as offering important measurements that can be used to test sophisticated evolving computational models and theories of droplet combustion.

Keywords Combustion - Droplet combustion . Microgravity · International space station · Experiments . Fire safety

\section{Introduction}

The spherically symmetrical combustion of a liquid fuel droplet in a quiescent ambient gaseous oxidizing atmosphere is a classical problem in combustion research, having been addressed first more than 50 years ago (Godsave 1952; Spalding 1952). Numerous reviews of the subject are now available in the literature (Williams 1973; Faeth 1977; Law 1982; Avedisian 2000; Choi and Dryer 2001). An advantage of spherical symmetry is that only one spatial dimension enters the description of the combustion process, so that the one-dimensional, time-dependent conservation equations apply. This greatly facilitates both computational and theoretical descriptions of the problem, thereby enhancing understanding of experimental results, which becomes much more difficult, uncertain and inaccurate in multidimensional situations.

In normal gravity natural convection destroys the spherical symmetry of the combustion process as was quite evident in the earliest experiments (Hall and Diederichsen 1953; Goldsmith 1956). Kumagai and Isoda (1956) were the first to realize that microgravity experiments afforded the opportunity to achieve spherical symmetry, a fact that NASA has exploited with fundamental investigations for a number of years (Williams 1981; Dietrich et al. 1996; Nayagam et al. 1998). These experiments have revealed important droplet burning phenomena including flame extinction, disruptive burning, etc. Even though much new understanding has been derived through microgravity experiments performed using drop-towers and aircrafts flying parabolic trajectories, the longer observation times available in space-based experiments are required to study droplets over a complete range of initial conditions (droplet size and ambient environment). Space experiments provide the opportunity to investigate phenomena such as departures from quasi-steady combustion, transition from diffusive to radiative extinction, liquid-phase transport, influence of convection on flame dynamics, effect of sooting, multicomponent droplets and flammability limits.
This article presents an overview of the results of the Flame-Extinguishment Experiments (FLEX). Results are presented for single droplets of heptane and methanol burning in ambient environments consisting of oxygen/nitrogen, oxygen/nitrogen/carbon dioxide and oxygen/nitrogen/helium mixtures, at ambient pressures ranging from 0.7 to $3.0 \mathrm{~atm}$ with the vast majority at $1.0 \mathrm{~atm}$ and below.

\section{Experiment Description}

Experiment Hardware

FLEX is the first experiment in the multi-purpose combustion facility developed at the NASA Glenn Research Center (GRC). The Combustion Integrated Rack (CIR) provides the combustion chamber, most of the diagnostics, gas mixing system and the primary interface between the ISS and the ground controllers at NASA GRC. The Multi-User Droplet Combustion Apparatus (MDCA), inserted into the $\mathrm{CIR}$, is the hardware that deploys and ignites the liquid fuel droplets. It communicates through the CIR to ground controllers at NASA GRC.

The CIR facility, occupying a large rack in the Destiny module of the ISS and described in detail elsewhere (Banu 2008), consists of a $90 l$ combustion chamber that is capable of operating pressures of approximately 0 - $9 \mathrm{~atm}$. The maximum pressure for a given experiment is frequently much less than $9 \mathrm{~atm}$ depending on a rigorous (and very conservative) safety analysis. For the FLEX experiments, this analysis reduced the maximum working pressures to approximately $3 \mathrm{~atm}$. The interior of the CIR chamber contains the mechanical, fluid and electrical interfaces necessary to mount experiment-specific hardware inside the chamber.

The CIR facility provides the capability to accurately control the ambient environment inside the chamber. This capability is provided by the Fuel and Oxidizer Mixing Apparatus (FOMA). The FOMA consists of gas bottles, pressure transducers and mass flow controllers to the combustion chamber. The contents of the chamber can be evacuated by a vacuum pump connected to the ISS overboard vent.

The hardware for the FLEX experiments is the MultiUser Droplet Combustion Apparatus (MDCA, Fig. 1). The MDCA facility (Robbins and Shinn 2010) is based on the design of the Space Shuttle Droplet Combustion Experiment (Nayagam et al. 1998). This MDCA is capable of deploying both free and fiber-supported droplets in a quiescent microgravity environment. The hardware for the deployment is $250 \mu \mathrm{m}$ outside diameter stainless-steel tubes with polished and fluted ends. The fluid is dispensed between the axially opposed needles and then slowly stretched to a 


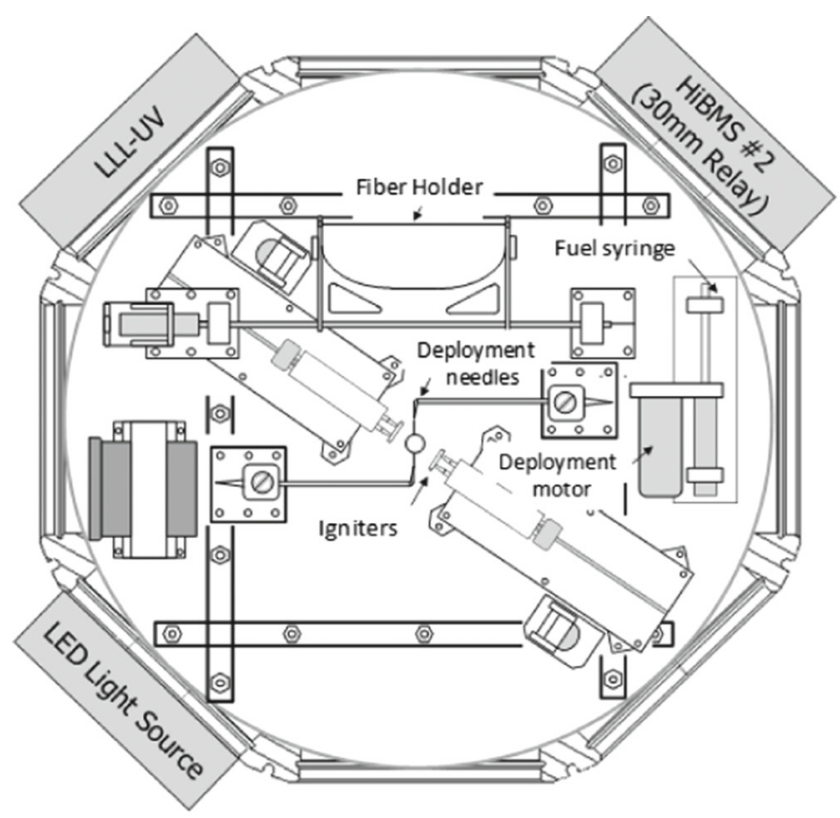

Fig. 1 Schematic of the Multi-user Droplet Combustion Apparatus (MDCA)

distance slightly smaller than the distance where the fluid would become detached from one of the needles. This stretch of the droplet between the needles minimizes the post-deployment drift velocity and internal circulation in the liquid. Just before ignition the needles rapidly retract, ideally leaving a motionless droplet floating in the middle of the CIR combustion chamber.

Once the needles retract, the control computer energizes two hot-wire igniters located 180 degrees to each other and in the same plane as the deployment needle assembly. After a preset time, the control computer de-energizes the igniters and activates the linear motors to retract them away from the droplet. For fiber-supported tests, the procedure is exactly the same except that the droplets are deployed onto a small $80 \mu \mathrm{m}$ Silicon-Carbide ( $\mathrm{SiC}$ ) support fiber.

Each needle is connected by flexible Teflon tubing to a fuel reservoir or cartridge. The fuel cartridges in the MDCA consist of a gas-tight syringe connected to a remotely actuated, gas-tight solenoid valve. The two reservoirs mounted in the MDCA are easily replaceable by the crew during nominal operations. For the experiments reported herein, each reservoir contained one of the fuels, heptane or methanol. The amount of fuel in the syringe was approximately $2.5 \mathrm{ml}$ for methanol and $1.25 \mathrm{ml}$ for heptane.

\section{Experiment Diagnostics}

The primary diagnostics for the FLEX experiment are provided by the CIR facility and described in detail elsewhere (Banu 2008). They include a backlit view of the droplet and an orthogonal view of the flame. The illumination for the backlit view is a red laser diode source and a collimating optical system. They provide monochromatic illumination with a center wavelength between $650-660 \mathrm{~nm}$. The laser diode operates below the lasing threshold current and thus acts as a non-coherent illumination source. The image system for the backlit view is the High Bit-Depth Multispectral (HiBMs) Package. The HiBMs Package has a telecetric imaging optical system and a high resolution 12-bit output digital camera. The HiBMS package is modular and can be configured on the ground and on-orbit with different lenses, filters, image configurations, etc.

Nearly all of the tests reported herein used the full 1024 x 1024 array with a fixed field of view of approximately $30 \mathrm{~mm}$ on a side. The images used the full $12 \mathrm{bits}$, and the framing rate was $30 \mathrm{fps}$. The HiBMS package, when used in conjunction with the illumination package, provided the capability of measuring the droplet size as a function of time and the soot volume fraction for soot-producing flames (i.e., heptane for the tests described in this report).

The CIR also provides a Low Light Level Ultra-Violet (LLLUV) Package to image the chemiluminescence from $O H^{*}$ of the burning droplet. The LLLUV package has a 1024 x 1024 monochrome frame transfer CCD array with 12 bit digital imaging capability. The CCD array is directly coupled to an $18 \mathrm{~mm}$ Gen-II-UV Micro-channel Plate Intensifier to provide maximum response at short wavelengths. The intensifier includes intensifier and gating control that allows varied exposure times depending on the expected brightness of the flames. The LLLUV also has a spectral bandpass filter to image the chemiluminescence at $310 \mathrm{~nm}$ (the filter has a $10 \mathrm{~nm}$ FWHM bandwidth). Ground control of the LLLUV enabled pre-test setting of the gain, pixel binning and gate to optimally image the flames surrounding the droplets. All of the tests reported herein used the $2 \times 2$ binned (512 x 512 array) with a fixed field of view approximately $50 \mathrm{~mm}$ on a side. The framing rate for the majority of the tests was $30 \mathrm{fps}$, with a smaller number at $15 \mathrm{fps}$ to attempt to improve flame contrast for very dim flames. The intensifier gain did vary somewhat over the tests in this report.

The final image view of the burning droplet is from a color camera. This camera view is augmented with illumination from a white LED located on the MDCA inside the CIR chamber. This camera has a zoom lens that provides the operators with a close-up view of the needles and droplet during droplet formation and stretch (providing near real-time feedback to maximize the success rate of the experiment). Immediately prior to droplet deployment and ignition the camera zooms out and the white LED turns off to provide an overview of the combustion process. The FOV of this camera is approximately $93 \mathrm{~mm} \times 70 \mathrm{~mm}$. This view provides flame size, shape and color information. This 
view is downlinked to the ground during nominal test point operations.

The entire CIR rack was mounted to the ISS through the Passive Rack Isolation System (PaRIS). The PaRIS isolated the CIR from any high frequency vibration or g-jitter that would disturb the experiment. The rack also had several Space Acceleration Measurement System (SAMS) heads mounted to it to monitor the acceleration level during the experiments. Examination of the SAMS data showed that the g-levels (across the frequency spectrum) were typically less than $10^{-5} g_{0}$ where $g_{0}$ is the acceleration due to gravity at sea level on earth.

\section{Data Analysis}

The digital data from the CIR cameras are stored digitally on the ISS until downlinked to the ground (typically within the same week of operation). The digital data, after de-compression, comes in the form of individual image files along with a file that contains the relevant timing information for all of the images.

Figure 2 shows a sequence of images for a burning heptane droplet from all of the CIR cameras, the left column being from the backlit image of the droplet, the center column from the LLUV, and the right from the color camera. The first row shows the droplet before deployment and the second row shows the powered ignitor coils (note the glow) prior to withdraw. Rows 3 and 4 in Fig. 2 show the droplet and flame midway through the burn and just before flame extinction, respectively. The other rows show the droplet and flame images after visible flame extinction, the meaning of which will be clear later.

The backlight in the droplet images makes the discrimination between the droplet and background relatively easy (except when excessive soot formation obstructs the visibility of the droplet boundary (Dembia et al. 2012)). After defining a suitable threshold level, the droplet diameter is the size that results from equating the measured area of the droplet to that of an equivalent circle (Struk et al. 1998). The average burning rate constant $(\bar{k})$ comes from a linear fit of the droplet-squared history between approximately $t=0.1 \tau_{b}$ and $0.9 \tau_{b}$, where $\tau_{b}$ is the total burn time (igniter withdraw to extinction or burnout).

The flame size (both from the LLUV and color camera) is much more difficult to measure than the droplet size. Many of the flames were near the detectable limit in both cameras, and as a result quite dim. The flame luminosity also changed throughout the test, typically being brighter early in the burn and very dim near flame extinction. Using a single threshold value to discriminate between the flame and the background was problematic. A value relevant near flame extinction overestimates the flame diameter earlier, and a value relevant early in the flame lifetime does not detect a dim flame near extinction. For most of the tests reported herein the flame diameter is that which results from equating the measured area of the flame to that of an equivalent circle. The computer determined the threshold level to discriminate the flame from the background automatically using an iterative selection method (Ridler and Calvard 1978). We found that this provided the best representation of the flame throughout the lifetime and represented the outer edge of the flame. For tests in which the flame area was too difficult to determine, the flame diameter was simply taken as the maximum dimension of the flame in the direction that exhibited the least noise throughout the test.

Figure 3 contains the results of the analysis of the droplet and flame histories for the test in Fig. 2. The plot shows the droplet diameter squared normalized by the initial diameter squared, flame diameter (upper curves) and flame standoff ratio (FSR),that is, the flame diameter normalized by the droplet diameter at the same time, all three variables as functions of the time normalized by the initial droplet diameter squared. For the last two variables results are shown for both the LLUV and color camera. The vertical line in Fig. 3, where the flame size approaches zero, indicates when visible flame extinction occurs. The value of $\bar{k}$ is approximately $0.38 \mathrm{~mm}^{\mathrm{s}} / \mathrm{s}$ in this test. After visible flame extinction the droplet drifts out of the field of view for a short period of time and then drifts back into the field of view. The reason that Fig. 3 exhibits a large period of time after visible flame extinction will be discussed in the following section.

\section{Results and Discussion}

\section{Heptane}

The FLEX experiments use heptane as a typical alkane fuel. Its chemistry is relatively well understood and there is a wealth of experimental data, primarily in drop-tower facilities, with which some of the results can be compared. The fuel is moderately sooting and thus allows for the development and validation of soot formation and destruction mechanisms.

The independent variable that most influenced heptane burning behavior was the initial droplet diameter. Fig. 4 shows two tests in the same ambient environment (air at 1.0 atm diluted with $5 \% \mathrm{CO}_{2}$ ). The plot in this instance is of the dimensional droplet diameter squared, flame diameter and FSR as functions of time. The smaller droplet was slightly larger than $2 \mathrm{~mm}$ and the larger droplet slightly larger than $3 \mathrm{~mm}$. The burning behavior was very different for the two droplets. The smaller droplet had an initially luminous yellow flame that quickly became a relatively bright blue. The flame size increased, reached a maximum midway through the burn and then decreased until the droplet 

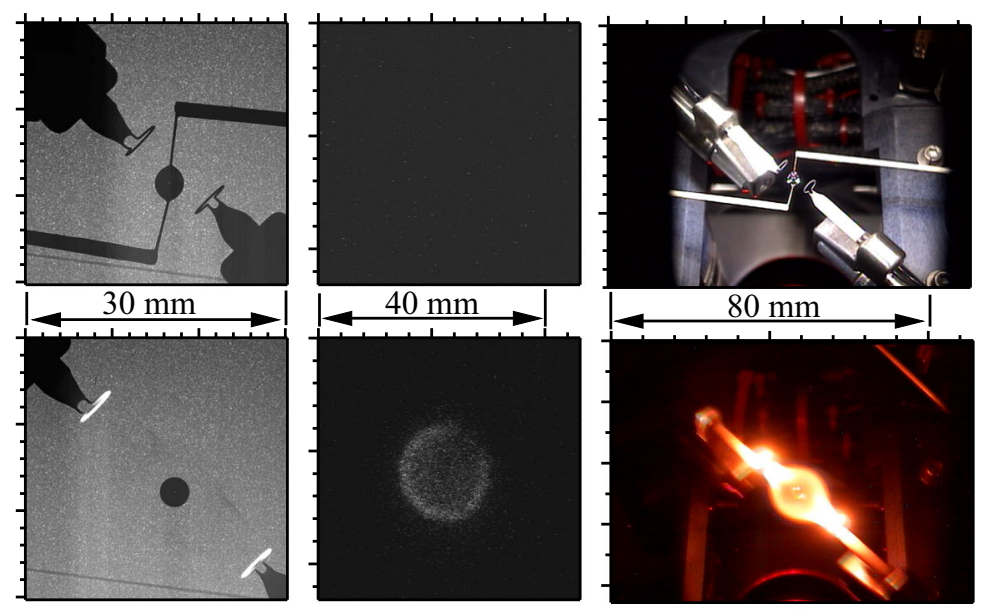

A: $\mathrm{t}=0.10 \mathrm{sec}$ before ignition
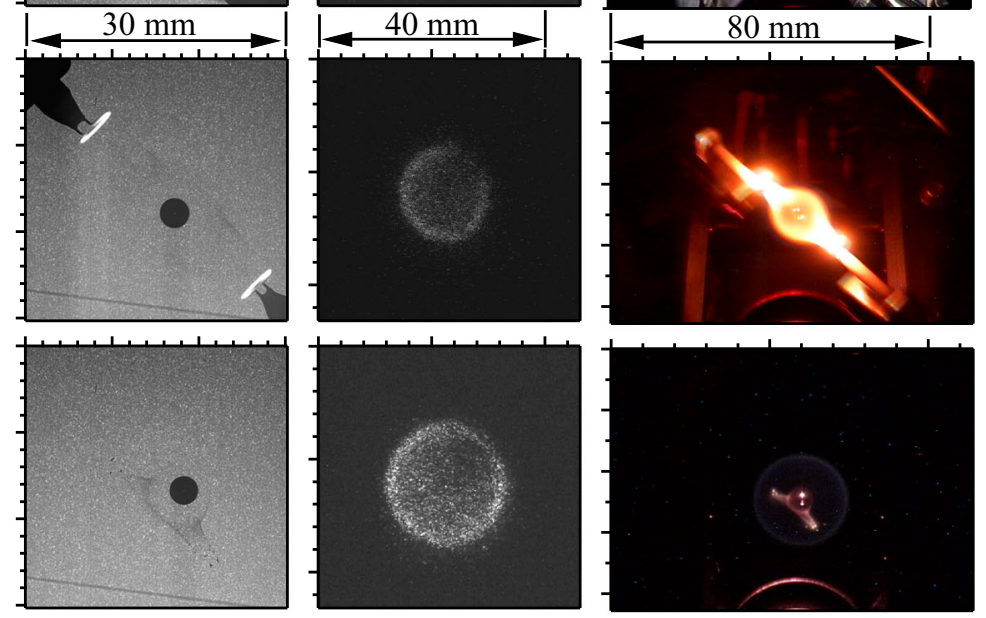

B: $\mathrm{t}=0.12 \mathrm{sec}$ after ignition
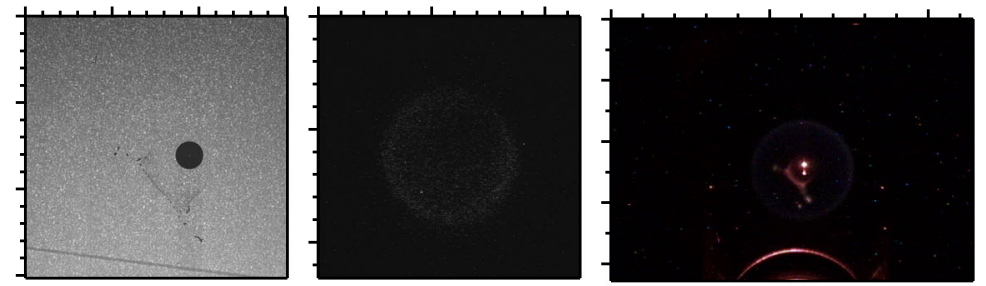

C: $\mathrm{t}=2.3 \mathrm{sec}$ after ignition
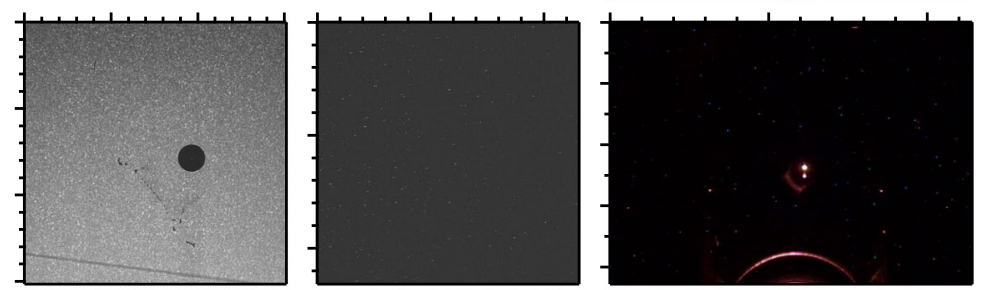

D: $\mathrm{t}=4.0 \mathrm{sec}$ after ignition

Just prior to visible flame extinction
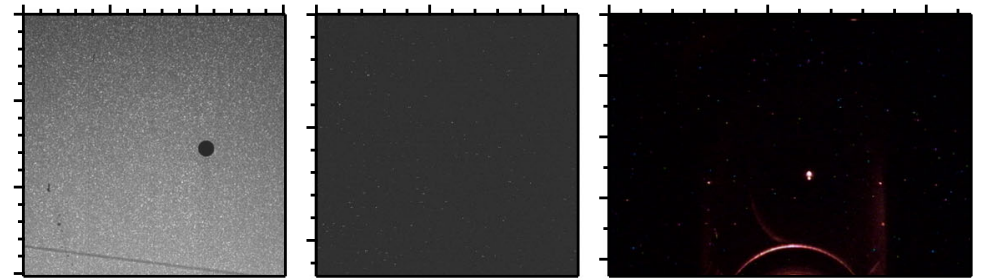

E: $\mathrm{t}=5.1 \mathrm{sec}$ after ignition

Immediately after visible flame extinction
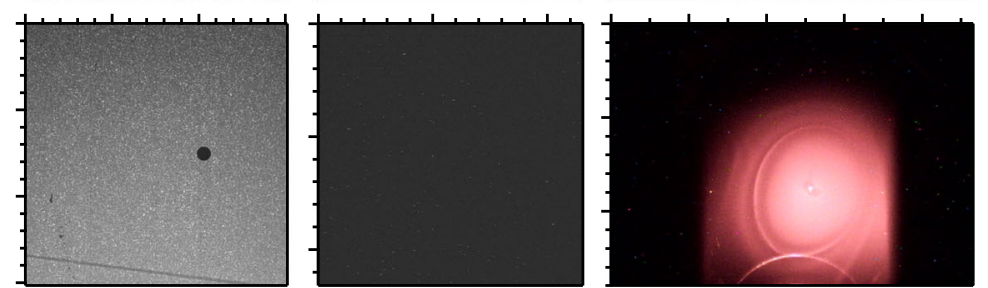

F: $\mathrm{t}=23.1 \mathrm{sec}$ after ignition

Just prior to plateau in droplet history

G: $\mathrm{t}=27.7 \mathrm{sec}$ after ignition

After plateau in droplet history

Fig. 2 FLEX image sequence for a heptane droplet from the three cameras corresponding to the times denoted by the dashed lines in the center column from the LLUV camera and the right column from the color camera. The ambient oxygen and nitrogen mole fractions were 0.18 and 0.72 , respectively and the ambient pressure was $1.0 \mathrm{~atm}$ 


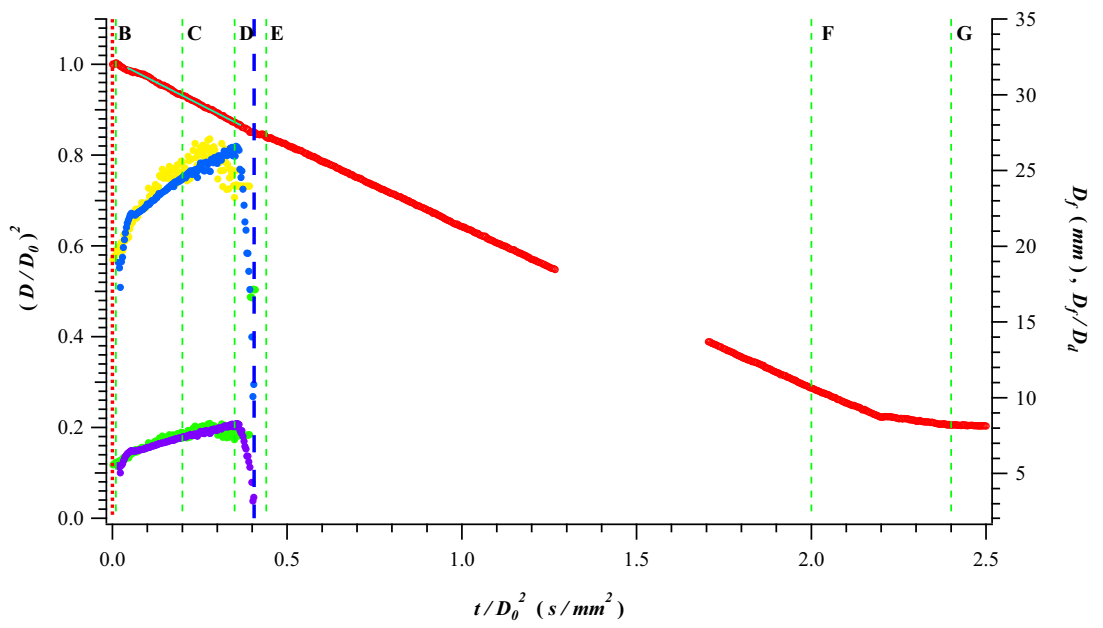

Fig. 3 Droplet and flame histories for the heptane droplet in Fig.2, initially $3.41 \mathrm{~mm}$ in diameter. The ambient environment had oxygen and nitrogen mole fractions of 0.18 and 0.72 , respectively and a pressure of $1.0 \mathrm{~atm}$. The gap in the droplet history at $t / D_{0}^{2} \sim 1.5$ is when the droplet drifted out of the field of view of the HiBMS camera (the drift velocity was on the order of $1-2 \mathrm{~mm} / \mathrm{s}$ ). The thin vertical lines with letters correspond to the different times of the image sequence in Fig.2. The thick dashed vertical line (coincident to when the flame diameter and standoff decrease quickly) is when visible flame extinction occurred disrupted at a very small size. Even though the flame size decreased through much of the flame lifetime, the flame standoff ratio (FSR) increased continuously (and relatively linearly) for the most of the test before falling off rapidly just before extinction (the smaller droplet drifts out of the HiBMS field of view before extinction). The $\bar{k}$ for this test was approximately $0.53 \mathrm{~mm}^{2} / \mathrm{s}$.

The larger droplet had a slightly smaller $\bar{k}\left(0.49 \mathrm{~mm}^{2} / \mathrm{s}\right)$ but very different flame behavior. The flame size grew continuously throughout the visible flame lifetime. In addition, after the initial ignition transient (where the flame is very luminous), the flame became very dim blue and the luminosity decreased continuously until flame extinction. The FSR increased continuously and nearly linearly throughout the test although the rate of increase for the larger droplet was smaller. The total duration of the visible flame for the two droplets was nearly the same.

Diffusive extinction was difficult to observe for heptane droplets. The estimated droplet diameter at diffusive extinction is quite small, and the experimental observations are that the droplet disrupts at a size larger than that diameter (the smaller droplet in Fig. 4). Radiative extinction, however, was frequently observed for heptane droplets (e.g. the larger droplet in Fig. 4). During radiative extinction, the flame extinction process is relatively slow. Local flame extinction begins preferentially on one side of the flame (typically on the side opposite to the direction of the droplet drift). The flame then slowly retreats over a number of video frames (5 - 10 frames typically) before completely disappearing.

Flames that radiatively extinguished also exhibited flame oscillations on occasion. When this occurred, the retreating flame would reach a minimum size then would rapidly flash back before it began to retreat again. The flame would then oscillate like this several times with increasing magnitude (change in flame size) until the flame completely extinguished. These oscillations were similar to those observed for candle flames (Dietrich et al. 2000) in microgravity and also observed during droplet combustion (Dietrich et al. 1996). An important feature of these oscillations is that they only occurred for tests where the extinction mode was radiative.

As the ambient oxygen mole fraction decreases, the droplet diameter at diffusive extinction increases and the droplet diameter for radiative extinction decreases. The ambient oxygen mole fraction at which they become equal is the limiting oxygen index (LOI). At ambient oxygen mole fractions lower than the LOI, quasi-steady burning does not occur. The experimental results show, however, that transient combustion is possible, more than likely enabled by the residual energy from ignition. For heptane in oxygen/nitrogen environments, the limiting oxygen index (LOI) is approximately 0.15 .

A number of the tests simulated the action of an inertgas fire suppressant in air by diluting carbon dioxide into a 0.21/0.79 $\mathrm{O}_{2} / \mathrm{N}_{2}, 1.0 \mathrm{~atm}$ ambient environment (making it a $\mathrm{O}_{2} / \mathrm{N}_{2} / \mathrm{CO}_{2}$ environment with a $\mathrm{O}_{2} / \mathrm{N}_{2}$ ratio of 0.27). For these $\mathrm{O}_{2} / \mathrm{N}_{2} / \mathrm{CO}_{2}$ tests, the LOI for heptane increased to approximately $0.17\left(0.63 / 0.20 \mathrm{~N}_{2} / \mathrm{CO}_{2}\right)$. The higher $\mathrm{LOI}$ in the $\mathrm{CO}_{2}$-diluted tests results from increased specific heat of carbon dioxide that decreases the flame temperature. Carbon dioxide is also a radiatively participating gas that also likely contributes to the increase in the $L O I$ by increasing the rate of radiant heat loss. For helium-diluted 
Fig. 4 Droplet and flame histories for two heptane droplets $\left(D_{0}=2.1,3.0 \mathrm{~mm}\right)$ burning in a $0.20 / 0.75 / 0.05$ $\mathrm{O}_{2} / \mathrm{N}_{2} / \mathrm{CO}_{2}, 1.0 \mathrm{~atm}$ ambient environment. The flame is that measured by the LLUV. The smaller droplet drifted out of the field of view before the end of the test. The vertical dashed lines indicate the time where flame extinction occurred; the dashed line at $20+s$ marks the approximate time of the second extinction. For clarity, the graphs show a subset (one of every five) of the experimental data

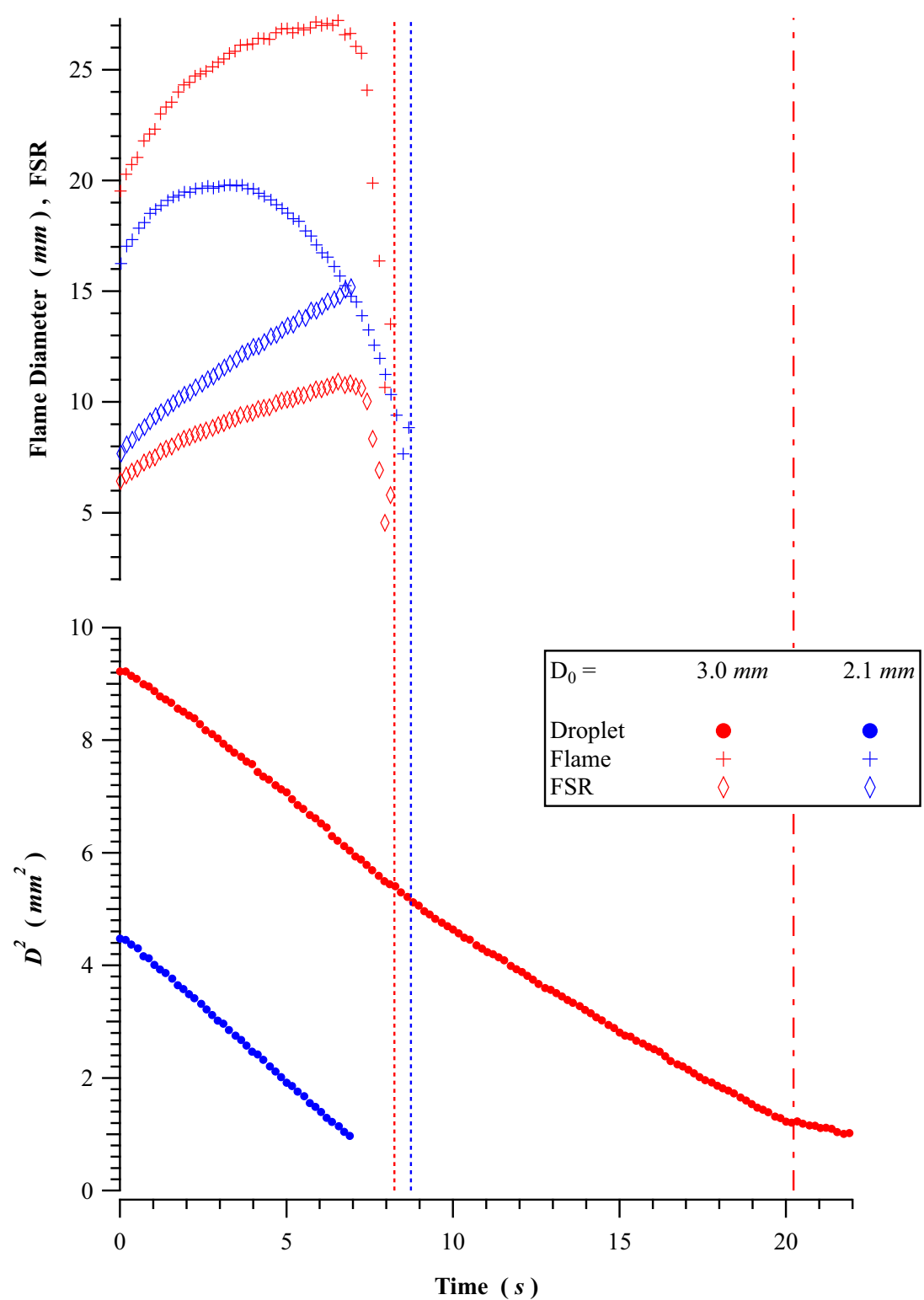

environments the LOI was approximately $0.15(0.63 / 0.20$ $\mathrm{N}_{2} / \mathrm{CO}_{2}$ ). These LOI values are consistent with groundbased work in reduced gravity with smaller heptane droplets (Shaw and Wei 2011) that found a LOI of $0.16 \pm 0.01$ for helium/air and $\mathrm{CO}_{2}$ /air ambients at $1 \mathrm{~atm}$ pressure.

The most unique finding for the heptane tests was what happened after radiative flame extinction for heptane. Both Figs. 3 and 4 show that after visible flame extinction the droplet vaporization continues (linear regression of diameter squared) for an extended period before an abrupt plateau near the end of the camera recording. The plateau in the droplet history slightly precedes the appearance of a very large vapor cloud in the color camera view (see Fig. 2). The linear vaporization behavior in this 'cool flame' region occurs as a result of low-temperature chemical reactions that somehow are initiated by the visible hot-flame extinction (Nayagam et al. 2012). This behavior is consistent with earlier results on combustion of large heptane/hexadecane droplets in 1-atm air that initially contained small amounts (as small as about $5.8 \%$ by mass) of hexadecane (Shaw et al. 2001). These droplets exhibited strong vaporization and appreciable radiometer signals after the early disappearance of visible flames, indicating continued chemical heat release from flames that could not be imaged with the available instrumentation. The present results suggest that these earlier-reported phenomena were not a result of the bi-component nature of the droplets.

Examining Fig. 4 in more detail shows that the droplet diameter during this cool-flame regime is in the same range as that during the smaller droplet test. This means that for a 
Fig. 5 Experimental (FLEX) and predicted (Farouk and Dryer 2013) droplet and flame histories for a heptane droplet $\left(D_{0}=3.9 \mathrm{~mm}\right)$ burning in a nominally air $(0.21$ oxygen mole fraction, balance nitrogen), 1.0 atm ambient environment. The numerical predictions contain both high and low temperature chemistry. For clarity, the graphs show a subset (one of every ten for the droplet, one of every five for the flame) of the experimental data

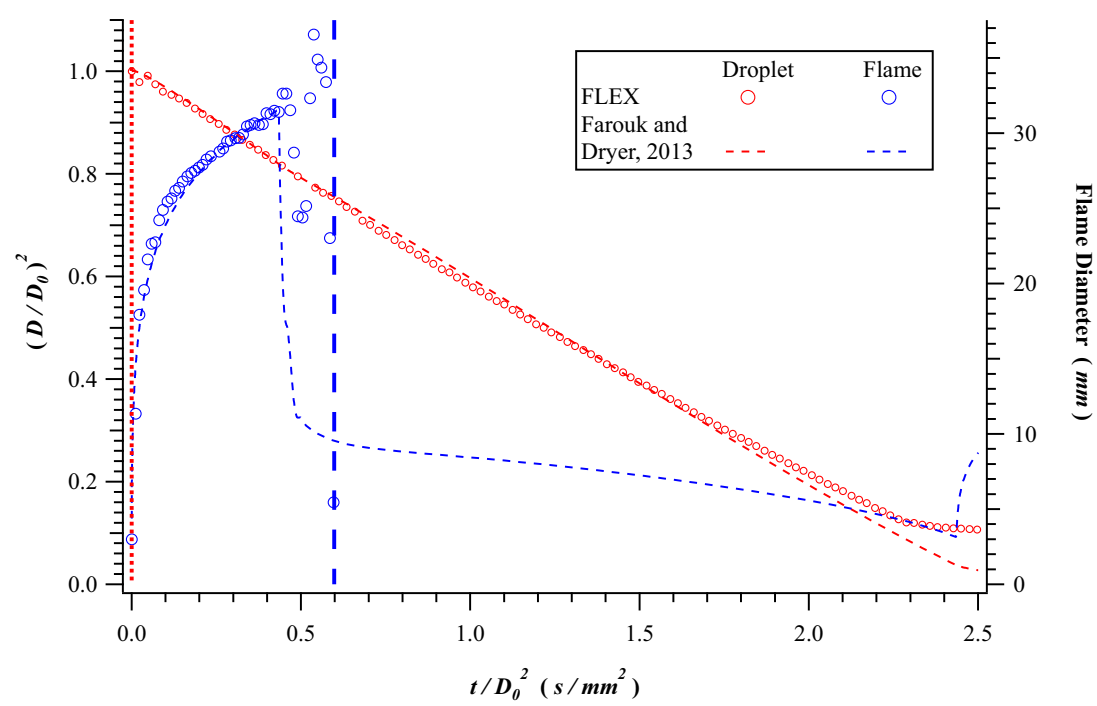

given size range a droplet can burn with either a hot flame or a cool flame, the initial condition determining which mode the droplet burns in. The cool flames were observed to occur in a wide range of ambient environments. This includes nominally air as well as atmospheres diluted with nitrogen, carbon dioxide and helium. A defining feature is that it only occurs after radiative extinction of the hot flame. Its occurrence is marked by vapor-cloud formation after cool-flame extinction.

Figure 5 shows a comparison of a heptane burn that exhibited a 'cool flame' with a numerical simulation (Farouk and Dryer 2013). The numerical predictions utilize a detailed chemical kinetics model containing both high and low temperature chemistry in a spherically-symmetric droplet combustion model. The predictions from the model for the droplet history capture the two stage combustion behavior; the visible extinction of the flame, transition to the second stage and self sustaining continuous combustion in the second stage. The numerical predictions show the peak gas temperature during the second stage to be approximately $700 \mathrm{~K}$, consistent with the presence of low temperature chemistry. The numerical predictions (Farouk and Dryer 2013) identify the radiative heat loss as being responsible for initiating the 'cool flame', consistent with the experimental observation (Nayagam et al. 2012). The model also predicts the presence of gaseous pure fuel vapor in addition to larger alkenes, ketohydroperoxides and cyclic ethers after 'cool flame' extinction that could condense to form the vapor cloud observed in the experiments.

\section{Methanol}

The FLEX experiments use methanol as a representative alcohol fuel. Its detailed chemistry is very well characterized, and there is an abundance of methanol data from ground-based microgravity facilities. These ground-based tests, however, must be limited to smaller initial droplet sizes (i.e., less than $1 \mathrm{~mm}$ diameter) if the entire burning history is to be captured.

Methanol droplets do not exhibit soot formation at the ambient pressures of the FLEX tests. The flame standoff distance is considerably smaller and as a result methanol does not extinguish radiatively at sizes as small as heptane. In fact, we seldom observed radiative extinction for methanol ${ }^{1}$. Methanol droplets do, however, exhibit diffusive extinction at considerably larger droplet diameters than heptane. This is a consequence of the combustion-generated water vapor that gets absorbed into the droplet during combustion (Dietrich et al. 1996; Zhang et al. 1996; Marchese and Dryer 1996; Nayagam et al. 2013). The extinction droplet diameters are relatively large and easily observed and determined.

Figure 6 shows the droplet and flame histories for three methanol droplets. The initial droplet diameter was 2.75 $m m( \pm 0.08 \mathrm{~mm})$ and the ambient oxygen and nitrogen mole fractions 0.21 and 0.49 , respectively. The primary difference between the tests was the dilution with different inert gases, nitrogen, carbon dioxide and helium. The $D^{2}$ curves are nearly linear over the majority of the droplet lifetime. The values of $\bar{k}$ for the nitrogen, carbon dioxide and helium diluted tests was $0.52,0.45$ and $0.70 \mathrm{~mm}^{2} / \mathrm{s}$, respectively. Detailed examination of the burning history does show that the instantaneous burning rate constant $\left(\frac{d}{d t}\left(D^{2}\right)\right)$ begins to decrease just prior to visible flame extinction. After visible

\footnotetext{
${ }^{1}$ We could have increased the droplet size to get radiative extinction. The experiments, however, are fuel-limited and given the cubic dependence of fuel volume on droplet diameter, the decision was made not to examine the radiative extinction at higher ambient oxygen mole fractions.
} 
Fig. 6 Droplet and flame histories for three methanol droplets with initial droplet sizes ranging from 2.67 to $2.83 \mathrm{~mm}$. The ambient oxygen and nitrogen mole fractions for all the tests were 0.21 and 0.49 , respectively. The balance was either nitrogen, carbon dioxide or helium. The ambient pressure was approximately $1.0 \mathrm{~atm}$ for the nitrogen and carbon dioxide diluted tests and $0.70 \mathrm{~atm}$ for the helium diluted test. The vertical dashed lines indicate the time when flame extinction occurred. For clarity, the graphs show a subset (one of every three) of the experimental data

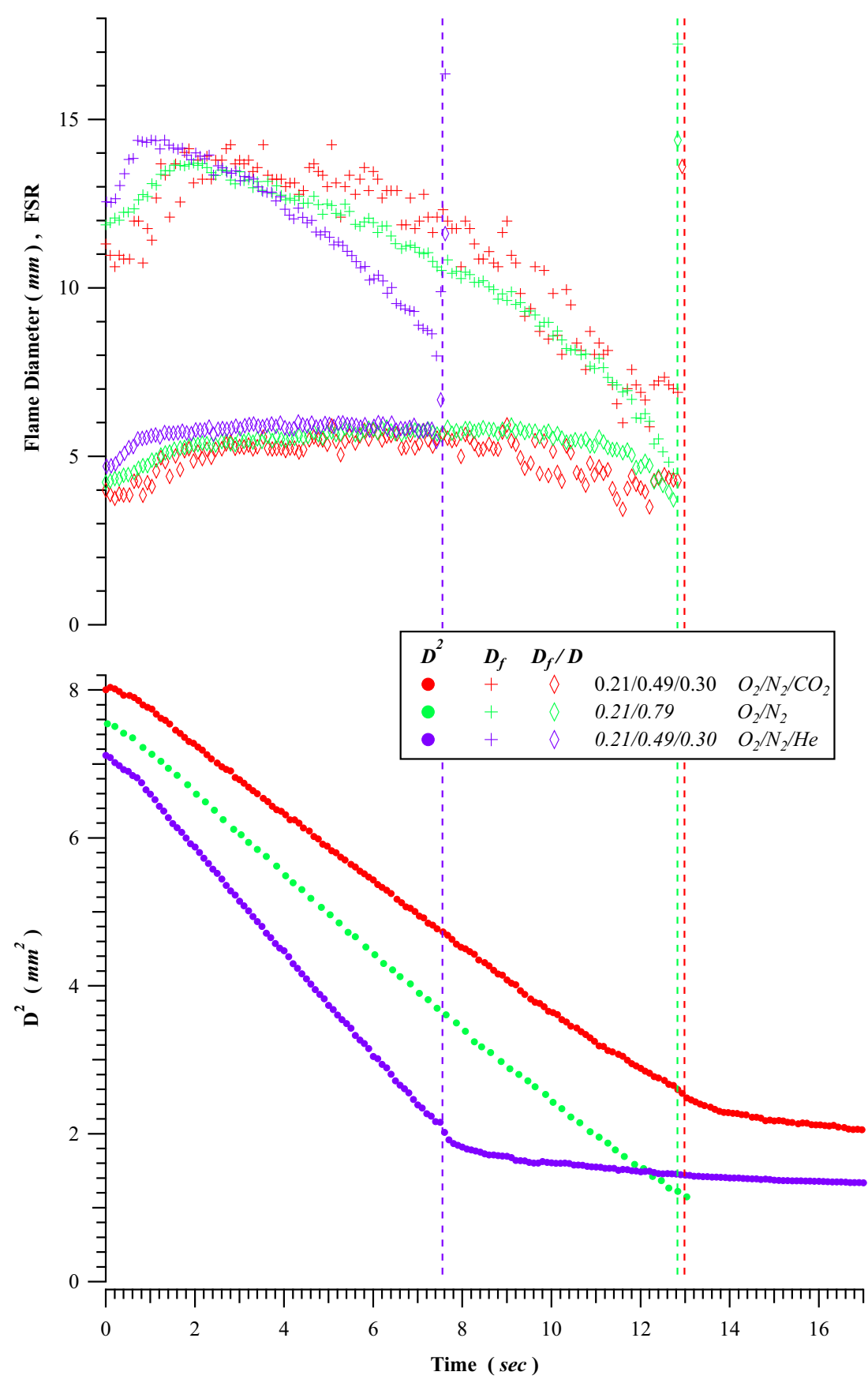

flame extinction, the decrease in vaporization rate is rapid and significant.

All of the flames for the tests in Fig. 6 extinguish diffusively. The characteristics of this extinction are somewhat different from those of the radiative extinction of the heptane droplets. For the diffusive extinction of methanol droplets the flame simply disappeared, at least within the time resolution of the available cameras. The flame was visible and surrounding the droplet in one frame and then gone in the next frame. For radiation extinction, however, the flame disappears in a more gradual way over several to many video frames.

The flame behavior prior to extinction was also different for the methanol droplets. Fig. 6 shows, representative of most methanol tests, that the flame size and FSR increase relatively quickly for a very short time ( $2 s$ or less). The flame size then decreases until flame extinction occurs. The increased scatter in the carbon-dioxide-diluted test in Fig. 6 is a result of the very dim flame that was near the detectable limit of the camera. The FSR is relatively constant for most 
Fig. 7 Flame standoff ratio (FSR) as a function of ambient oxygen mole fraction (balance nitrogen) for methanol droplets in the FLEX experiments.

Droplet size and ambient pressure are not delineated on the plot

Fig. 8 Extinction droplet diameter as a function of initial droplet diameter for methanol droplets in a nominally air ambient (1.0 atm, 0.21/0.79 oxygen/nitrogen mole fraction) environment. The datum points are from the FLEX experiments and the lines theoretical (Nayagam et al. 2013) and numerical (Farouk and Dryer 2012b) predictions of the experiments
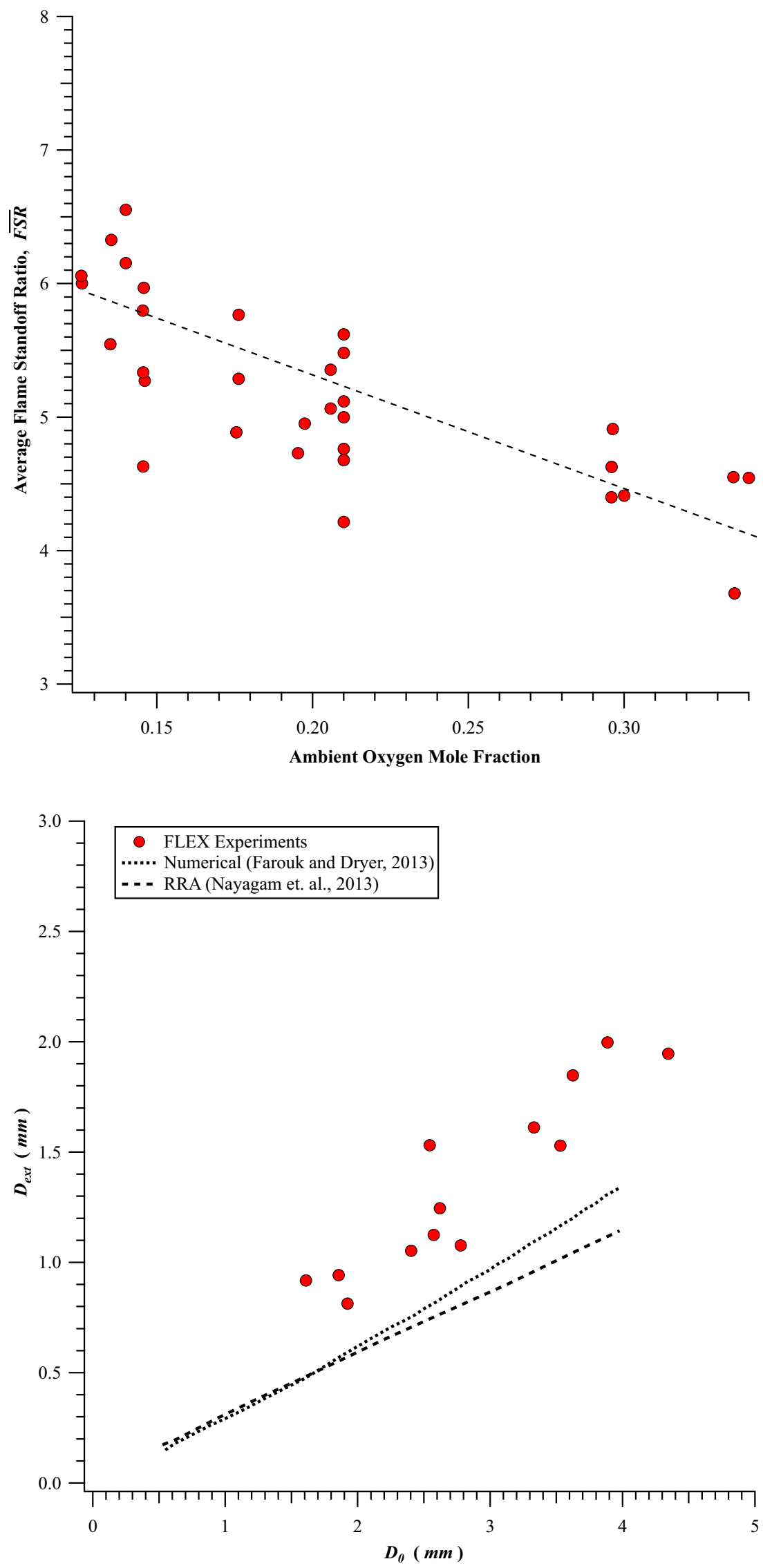
of the droplet lifetime, decreasing slightly just before flame extinction.

From Fig. 6 we define a quasi-steady FSR as the average flame standoff ratio $(F \bar{S} R)$ from the time just after the ignition transient subsides to before the FSR begins to decrease just before visible flame extinction. This ratio is seen in Fig. 6 to be about 5 in all three atmospheres. There are, however, variations of this value with the initial droplet size and with the composition of the atmosphere. Fig. 7 shows the $F \bar{S} R$ as a function of the ambient oxygen mole fraction in oxygen/nitrogen environments. There is obviously quite a bit of scatter in Fig. 7, although there is an unmistakable trend of decreasing $F \bar{S} R$ with increasing ambient oxygen mole fraction, consistent with expectations from Burke-Schumann theory. The scatter is primarily a result of variations of the initial droplet size and ambient pressure, none of which are indicated in Fig 7. For example, the scatter at the lower ambient oxygen mole fractions is due to variations in the initial droplet diameter. Larger droplets burned to radiative extinction relatively transiently, and the FSR does not reach a quasi-steady value.

All three of the droplets in Fig. 6 extinguish diffusively. For methanol, unlike heptane ${ }^{2}$, because of the water absorption, the droplet diameter at diffusive extinction is calculated to increase with increasing initial diameter. Figure 8 shows the extinction droplet diameter as a function of initial diameter for methanol droplet combustion in a nominally air ambient (1.0 atm pressure, 0.21/0.79 oxygen/nitrogen ambient mole fractions). Figure 8 shows only a small subset of all the methanol data which encompass a wide range of ambient oxygen mole fractions, inert gas diluents and ambient pressures. The two dashed lines in Fig. 8 show theoretical (from rate ratio asymptotics, RRA, Nayagam et al, 2013) and numerical (Farouk and Dryer 2012b) predictions of methanol droplet diffusive extinction diameters in air.

The flames surrounding methanol droplets occasionally oscillated before radiative flame extinction, although those oscillations were not as prevalent as in the heptane experiments. The LOI for methanol in oxygen/nitrogen ambient environments was approximately 0.12 . For tests that involved diluting carbon dioxide into a $0.21 / 0.79$ $\mathrm{O}_{2} / \mathrm{N}_{2}, 1.0 \mathrm{~atm}$ ambient environment the LOI increased to approximately $0.14\left(0.56 / 0.30 \mathrm{~N}_{2} / \mathrm{CO}_{2}\right)$. The LOI was approximately the same for helium-diluted atmospheres $\left(0.14 / 0.56 / 0.35 \mathrm{O}_{2} / \mathrm{N}_{2} / \mathrm{CO}_{2}\right)$. These LOI values are consistent with ground-based work in reduced gravity with smaller methanol droplets (Shaw and Wei 2012) that found a LOI of $0.15 \pm 0.02$ for helium/air and $\mathrm{CO}_{2}$ /air ambients at $1 \mathrm{~atm}$ pressure.

\footnotetext{
${ }^{2}$ Theoretically, the droplet diameter at diffusive extinction for heptane is independent of the initial diameter.
}

A subset of the FLEX experiments also utilized small $80 \mu \mathrm{m} \mathrm{SiC}$ support fibers to keep the droplet position fixed. The data from those experiments are useful for better understanding the influence of the support fiber in droplet combustion experiments and in validating tethered droplet combustion models (Farouk and Dryer 2012a).

\section{Conclusions}

This paper presented the results of methanol and heptane isolated droplet combustion experiments conducted on the International Space Station. The long burn times of many of the experiments (droplet formation, ignition, quasi-steady burning and flame extinction) show that these types of experiments can only be conducted in the facilities that offer relatively long times of high quality microgravity. The complete data set from the experiments will ultimately be analyzed and archived for public use.

The experiments show both radiative and diffusive extinction and further identify the limiting oxygen index for both oxygen/nitrogen and oxygen/nitrogen/carbon dioxide ambient environments. For many experiments where radiative extinction occurred, the flames oscillated briefly at a frequency of approximately $1 \mathrm{~Hz}$ before flame extinction. These oscillations were not observed for diffusive extinction.

The experiments also uncovered the existence of a new burning regime for heptane droplets. For large heptane droplets after the visible hot flame radiatively extinguishes the droplet continues to burn with a cool flame. These cool flames occur over a wide range of ambient conditions. This observation would not have been possible without access to a long-duration, high-quality microgravity environment.

Acknowledgements The authors wish to express their sincere gratitude to the management, engineering and operations teams at NASA and Zin Technology, Inc. and the ISS astronauts who participated in the experiments.

\section{References}

Avedisian, C.T.: Recent advances in soot formation from spherical droplet flames at atmospheric pressure. J. Propul. Power 16(4), $628-635$ (2000)

Banu, B.: Fluids and combustion facility (FCF) and combustion integrated rack (CIR). Payload Accomodations Handbook CIR-DOC4064, NASA John H, Glenn Research Center, Cleveland, Ohio (2008)

Choi, M.Y., Dryer, F.L.: Microgravity droplet combustion. In: Ross, H.D. (ed.): Microgravity combustion: fire in free fall, combustion treatise, pp. 183-297. Academic Press (2001). chap. 4

Dembia, C.L., Liu, Y.C., Avedisian, C.T.: Automated data analysis for consecutive images from droplet combustion experiments. Image Anal. Stereology 31, 137-148 (2012) 
Dietrich, D.L., Haggard, J.B., Dryer, F.L., Nayagam, V., Shaw, B.D., Williams, F.A.: Droplet combustion experiments in spacelab. Proc. Combust. Inst. 26, 1201-1207 (1996)

Dietrich, D.L., Ross, H.D., Shu, Y., Chang, P., Tien, J.S.: Candle flames in nonbuoyant atmospheres. Combust. Sci. Tech. 156, 124 (2000)

Faeth, G.M.: Current status of droplet and liquid combustion. Prog. Energy Combust. Sci. 3, 191-224 (1977)

Farouk, T., Dryer, F.L.: Tethered methanol droplet combustion in carbondioxide enriched environment under microgravity conditions. Combust. Flame 159(1), 200-209 (2012a)

Farouk, T.I., Dryer, F.L.: On the extinction characteristics of alcohol droplet combustion under microgravity conditions - a numerical study. Combust. Flame 159(10), 3208-3223 (2012b)

Farouk, T.I., Dryer, F.L.: Isolated n-heptane droplet combustion in microgravity: Cool Flames = two-stage combustion. Combust. Flame 161, 565-581 (2013)

Godsave, G.A.E.: Studies of the combustion of drops in a fuel spray the burning of single drops of fuel. Proc. Combust. Inst. 4, 818830 (1952)

Goldsmith, M.: Experiments on the burning of single drops of fuel. Jet Propuls. 26, 172-178 (1956)

Hall, A.R., Diederichsen, J.: An experimental study of the burning of single drops of fuel in air at pressures up to twenty atmospheres. Proc. Combust. Inst. 4, 837-846 (1953)

Kumagai, S., Isoda, H.: Combustion of fuel droplets in a falling chamber. Proc. Combust. Inst. 6, 726-731 (1956)

Law, C.K.: Recent advances in droplet vaporization and combustion. Prog. Energy Combust. Sci. 8, 171-201 (1982)

Marchese, A.J., Dryer, F.L.: The effect of liquid mass transport on the combustion and extinction of bicomponent droplets of methanol and water. Combust. Flame 105, 104-122 (1996)

Nayagam, V., Haggard, J.B., Colantonio, R.O., Marchese, A.J., Dryer, F.L., Zhang, B.L., Williams, F.A.: Microgravity n-heptane droplet combustion in oxygen-helium mixtures at atmospheric pressure. AIAA J. 36(8), 1369-1378 (1998)
Nayagam, V., Dietrich, D.L., Ferkul, P.V., Hicks, M.C., Williams, F.A.: Can cool flames support quasi-steady droplet burning Combust. Flame 159, 3583-3588 (2012)

Nayagam, V., Dietrich, D.L., Hicks, M.C., Williams, F.A.: Methanol droplet combustion in oxygen-inert environments in microgravity. In: 8th US National combustion meeting, Western States section of the Combustion Institute, Salt Lake City, Utah, paper 070HE-0303 (2013)

Ridler, T.W., Calvard, S.: Picture thresholding using an iterative selection method. IEEE Trans. Syst. Man Cybern. SMC-8(8), 230-232 (1978)

Robbins, J., Shinn, C.: Multi-user droplet combustion apparatus FLEX-2. Reflight Safety Data Package MDC-DOC-1790A, NASA John H. Glenn Research Center, Cleveland, Ohio (2010)

Shaw, B., Wei, J.: Combustion of methanol droplets in air-diluent environments with reduced and normal gravity. J. Combust. 2012(Article ID 587987) (2012)

Shaw, B.D., Wei, J.B.: Influence of gravity and ambient pressure on combustion and flammability of n-heptane and 1-propanol droplets in air-diluent environments. Combust. Sci. Tech. 183(10), 969-983 (2011)

Shaw, B.D., Clark, B.D., Wang, D.: Spacelab experiments on combustion of heptane/ hexadecane droplets. AIAA J. 39(12), 2327-2336 (2001)

Spalding, D.B.: The combustion of liquid fuels. Proc. Combust. Inst. 4, 847-864 (1952)

Struk, P.M., Ackerman, M., Nayagam, V., Dietrich, D.L.: On calculating burning rates during fiber supported droplet combustion. Microgravity Sci. Tech. XI/4, 144-151 (1998)

Williams, A.: Combustion of droplets of liquid fuels: a review. Combust. Flame 21, 1-31 (1973)

Williams, F.A.: Droplet burning, In: Cochran, T. H. (ed) Progress in Astronautics and Aeronautics, vol 73, American Institute of Aeronautics and Astronautics, chap. 2, pp. 3160 (1981)

Zhang, B.L., Card, J.M., Williams, F.A.: Application of rate-ratio asymptotics to the prediction of extinction for methanol droplet combustion. Combust. Flame 105, 267-290 (1996) 